\title{
Preliminary study of the presence of antibodies against excretory- secretory antigens from protoscoleces of Echinococaus granulosus in dogs with intestinal echinococcosis
}

\author{
D avid Carmena/ ${ }^{++}$, Aitziber Benito, Jorge Martínez, Jorge A G uisantes/ ${ }^{+}$
}

Departamento de Inmunología, Microbiología y Parasitología, Facultad de Farmacia, Universidad del País Vasco, Apartado 450, 01080-Vitoria, España

The aim of the present study was to analyze the antibody response against excretory-secretory antigens (ES-Ag) from Echinococcus granulosus protoscoleces, using sera from dogs infected with E. granulosus and other helminths. ES-Ag were obtained from the first $50 \mathrm{~h}$ maintenance of protoscoleces in vitro. Immunochemical characterization was performed by immunoblotting with sera from dogs naturally infected with $\mathrm{E}$. granulosus $(n=12)$, sera from dogs infected with helminths other than E. granulosus $(n=30)$, and helminth-free dog sera $(n=20)$. These findings were compared to those obtained from a somatic extract of protoscoleces ( $S$-Ag). ES-Ag only showed four cross-reacting proteins of 65, 61, 54, and 45-46 kDa. Antigens with apparent masses of 89 and $50 \mathrm{kDa}$ in ES-Ag and of 130 and 67 $k D a$ in $S$-Ag were identified by sera of dogs infected with E. granulosus only, whereas a protein of 41-43 kDa was recognised by the majority of the sera from dogs with non-echinococcal infection. Employing ELISA to study the same sera, S-Ag revealed higher immunoreactivity than ES-Ag, but also showed higher cross-reactivity levels when sera from dogs with non-echinococcal infection were assayed in immunoblotting.

Key words: Echinococcus granulosus - excretory-secretory antigens - protoscoleces - intestinal echinococcosis parasite antigens

Cystic hydatid disease in man is a zoonosis caused by infection with the larval stage of the dog tapeworm Echinococcus granulosus. The adult worm lives in the small intestine of dogs and other canids, in intimate contact with the intestinal epithelium. Parasite eggs (the infective stage for the intermediate host) are excreted in faeces, and may thus contaminate soil, grass and water. Detection of E. granulosus adults in dogs is very important in order to evaluate its prevalence and to develop surveillance and control programmes for hydatidosis/echinococcosis (WHO 2001). Diagnosis of taeniid cestode infections in dogs can be carried out using arecoline hydrobromide, but this technique has a highly variable sensitivity, is time consuming and some dogs suffer undesired side-effects (Wachira et al. 1990). Coprological exams, however, have low sensitivity since excretion of the eggs occurs sporadically. Furthermore, the eggs of taeniid cestodes are morphologically indistinguishable by light microscopy.

In an attempt to improve the sensitivity of $E$. granulosus diagnostics, different serological tests have been developed, mainly based on the detection of specific IgG

Financial support: FIS, Ministry of Public Health; DEMSAC, Town Council of Vitoria, and Department of Health, Basque Government

${ }^{+}$Corresponding author. E-mail: oipgudej@vc.ehu.es

${ }^{++}$Present address: MRC Clinical Sciences Centre, Membrane Transport Biology Group, Hammersmith Hospital Campus, Du Cane Road, London W12 0NN, UK

Received 17 February 2005

Accepted 27 April 2005 antibodies against the adult parasite. Somatic extracts of protoscoleces $(\mathrm{S}-\mathrm{Ag})$ are the most commonly used antigenic source. However, ELISA results showed highly variable sensitivities, ranging from 40 to $90 \%$ (Jenkins et al. 1990, Gasser et al. 1992, 1993, 1994). These studies also demonstrated that $25-60 \%$ of the sera from dogs infected with E. granulosus did not show significant levels of specific antibody (Jenkins et al. 1990, Gasser et al. 1994), and that cross-reactivity with other parasite species may occur (Gasser et al. 1988).

During recent years, diagnosis of intestinal echinococcosis has been mainly based on the detection of excretory-secretory products of E. granulosus protoscoleces in dog faeces using ELISA (Allan et al. 1992, Deplazes et al. 1992, Jenkins et al. 2000). This technique considerably improves both diagnostic sensitivity and specificity, permits the detection of the parasite during the prepatent period and shows the current status of the infection (Fraser \& Craig 1997).

Although characterization of somatic antigens of $E$. granulosus protoscoleces for diagnostic purposes has been described in several reports (Gasser et al. 1989, 1991, 1992, Rafiei \& Craig 2002), very little information is available about excretory-secretory products of protoscoleces (Gasser et al. 1992, Carmena et al. 2004). In this preliminary work we show the presence of antibodies that recognize excretory-secretory antigens of E. granulosus protoscoleces in sera from dogs infected with $E$. granulosus and other helminths. Some of the described components could be promising candidate antigens for immunodiagnosis of dog echinococcosis. These results were compared with those obtained for somatic extracts, the antigenic source that has mainly been used in the serodiagnosis of intestinal echinococcosis. 


\section{MATERIALS AND METHODS}

Somatic antigens $(S-A g)$ - E. granulosus parasite material was isolated from sheep hepatic hydatid cysts collected from an abattoir in La Rioja, Spain. Somatic antigens were obtained from protoscoleces removed by aseptic cyst puncture as described by Smyth and Davies (1974), washed with phosphate-buffered saline (PBS) and stored at $-20^{\circ} \mathrm{C}$ with proteolytic enzyme inhibitors $(2 \mathrm{mM}$ PMSF and $5 \mathrm{mM}$ EDTA). Protoscoleces were thawed and sonicated (10 cycles of $12 \mathrm{~s}$ at $60 \mathrm{~Hz}$ frequency), freeze-thawed once more and centrifuged for $35 \mathrm{~min}$ at $2300 \times \mathrm{g}$. Supernatants were aliquotted and stored at $-20^{\circ} \mathrm{C}$.

Excretory-secretory antigens (ES-Ag) - To obtain excretory-secretory products, protoscoleces with viability higher than $90 \%$ were selected. Viability was assessed by morphological appearance, flame cell motility and general contractile movements (Smyth \& Davies 1974, Howell 1986). Protoscoleces were cultured in PBS complemented with $10 \%$ glucose, $100 \mathrm{U}$ ml-1 penicillin and $100 \mu \mathrm{g} \mathrm{ml}-1$ streptomycin at $37^{\circ} \mathrm{C}$ in $5 \% \mathrm{CO}_{2}$, which promoted parasite survival for several days (Carmena et al. 2002). Every $8 \mathrm{~h}$ the medium was removed and replaced with fresh medium. Protein recovery from the media was achieved by using Ultrafree 15 filters with a $5 \mathrm{kDa}$ pore diameter membrane (Millipore, Bedford, US). EDTA (5 mM) and PMSF ( $2 \mathrm{mM})$ were added, and the ES products were aliquotted and stored at $-20^{\circ} \mathrm{C}$. Protein concentration was determined by the bicinchoninic acid method (Sigma-Aldrich, Dorset, UK). In total, 8 cultures of hepatic protoscoleces from sheep were carried out. Medium corresponding to the first $50 \mathrm{~h}$ of culture was subsequently used. The concentration for proteins obtained for each preparation was: ESAg: $0.2 \mathrm{mg} \mathrm{ml}^{-1}$ and S-Ag: $2.95 \mathrm{mg} \mathrm{ml}^{-1}$.

Enzyme linked immunosorbent assay (ELISA) - ELISA was carried out as described by Benito et al. (2001). The following optimal antigen concentrations were used: ESAg: $20 \mu \mathrm{g} \mathrm{ml}^{-1}$ and S-Ag: $7.5 \mu \mathrm{g} \mathrm{ml}^{-1}$. Microtitre plates (Maxisorp $^{\mathrm{TM}}$, Nunc, Roskilde, Denmark) were coated with antigenic extract diluted in PBS buffer $(100 \mu \mathrm{l} /$ well $)$ and incubated overnight at $4^{\circ} \mathrm{C}$. Blocking was carried out with PBS-1\% bovine serum albumin (BSA, $200 \mu \mathrm{l} /$ well) for $1 \mathrm{~h}$ at $37^{\circ} \mathrm{C}$. Dog sera were tested in PBS- $0.5 \%$ BSA buffer $(100 \mu \mathrm{l} /$ well) using serial dilutions ranging from 1:50 to 1:200 in duplicate. The plates were incubated for $1 \mathrm{~h}$ at $37^{\circ} \mathrm{C}$. Peroxidase-conjugated rabbit anti-dog IgG (Sigma) was used at 1:1000 dilution in PBS-4\% SAB-0.05\% Tween 20 buffer for $1 \mathrm{~h}$ at $37^{\circ} \mathrm{C}$. Binding was visualised with 5aminosalicilic acid. The reaction was stopped by adding $25 \mu \mathrm{l} / \mathrm{well} \mathrm{NaOH} 1 \mathrm{~N}$, and the absorbance value was measured at $450 \mathrm{~nm}$.

SDS-PAGE and immunoblotting - Proteins were separated by $12.5 \%$ SDS-PAGE under reducing conditions according to Laemmli (1970). For immunoblotting, proteins were transferred to polyvinylidene difluoride (PVDF) membranes (Immobilon-P, Millipore), according to Towbin et al. (1979). Primary sera were used at 1:50 in $20 \mathrm{mM}$ Trisbuffered saline ( $\mathrm{pH} 7.4$ ), 8\% skimmed milk (TBS-M), incubating overnight at $4^{\circ} \mathrm{C}$. Peroxidase-conjugated rabbit anti$\operatorname{dog}$ IgG (Sigma) was used at 1:1000 in TBS-M buffer for 4 $\mathrm{h}$ at room temperature, and binding was visualised with 4chloro-1-napthol.

Dog sera - Include: a) dog sera obtained from the Council Animal Rescue Mission of Vitoria, Spain. All animals were diagnosed by autopsy, but their previous infection history was unknown. Five sera from dogs naturally infected with E. granulosus were obtained, with worm burdens ranging from 2 to 155 helminths. Thirty sera were obtained from dogs that harboured infections with Taenia spp. (including T. hydatigena and T. pisiformis), Mesocestoides spp., Dipylidium caninum, Toxocara canis, Toxascaris leonina, Trichuris vulpis, Uncinaria stenocephala, and Ancylostoma caninum. Sera from 20 helminth-free dogs that were under 2 years of age at the time of autopsy were also used; b) seven serum samples from farm dogs naturally infected with $E$. granulosus in the Chubut Province (Argentina). These samples were diagnosed by identifying worms following arecoline purgation, and were kindly provided by Dr Eduardo Fernández, Laboratorio de Control de Patologías Prevalentes, Hospital Zonal de Trelew, Chubut, Argentina; c) 20 sera from 5 dogs experimentally infected with $E$. granulosus, kindly provided by Dr P Spinelli, Instituto de Higiene, Montevideo (Uruguay). Animals had been orally infected with 60,000 protoscoleces (Spinelli et al. 1996) and four serum samples were obtained at day 0 and days 5,15 , and 29 post-infection. A pool of sera from dogs with E. granulosus natural infections was also used as a positive control in ELISA assays, with an assigned value of 8000 arbitrary units $\mathrm{ml}^{-1}$ (Benito et al. 2001).

Statistical methods - ELISA results were analyzed by means of variance analysis (ANOVA), using SPSS 11.5 statistical software.

\section{RESULTS}

Immunoblotting - Fig. 1 shows an analysis of recognition of individual components of ES-Ag and S-Ag with the 12 sera from dogs naturally infected with $E$. granulosus. These sera identify seven major components in the ES-Ag, standing out those of 89,46 , and $50 \mathrm{kDa}$. With regard to $\mathrm{S}-\mathrm{Ag}$, the same sera recognize 15 antigenic proteins, the most prominent being those of $67,55,48,43,39$, and $24 \mathrm{kDa}$. Figs 2 and 3 show the antigenic profiles of the ES-Ag and S-Ag identified with sera from dogs infected with other helminths, as well as with sera from helminthfree dogs. Proteins of 41-43 kDa and $85 \mathrm{kDa}$, both shared by ES-Ag and S-Ag, were recognized by many of these sera. Table I summarizes the data obtained by immunoblotting.

ELISA - ELISA results for sera from dogs naturally infected with E. granulosus are shown in Fig. 4. Using ES-Ag as solid phase, sera from dogs with higher worm burdens revealed lower specific antibody levels than sera from dogs infected with low numbers of $E$. granulosus. Similar results were obtained with S-Ag: the highest antibody titre was reached by the serum from dog number 4 , where only two worms were found at autopsy. However, no significant differences were found between the means of the absorbance values obtained for both antigenic extracts $(P<0.05)$. 
Fig. 5 summarizes the ELISA results for the 20 sera from dogs experimentally infected with $E$. granulosus. The highest specific antibody levels were observed for the bleeds obtained at days 15 and 29 post-infection from dogs 1 and 2. S-Ag was the most immunoreactive extract and also showed more homogeneous absorbance values among the studied sera than the ES-Ag. Regarding the sera from dogs naturally infected with $E$. granulosus, no significant differences were found between the means of the absorbance values obtained for both antigenic extracts $(P<0.05)$.

\section{DISCUSSION}

Excretory-secretory products from scoleces and adults of E. granulosus have been previously assayed as an antigenic source for immunodiagnosis of canine echino-

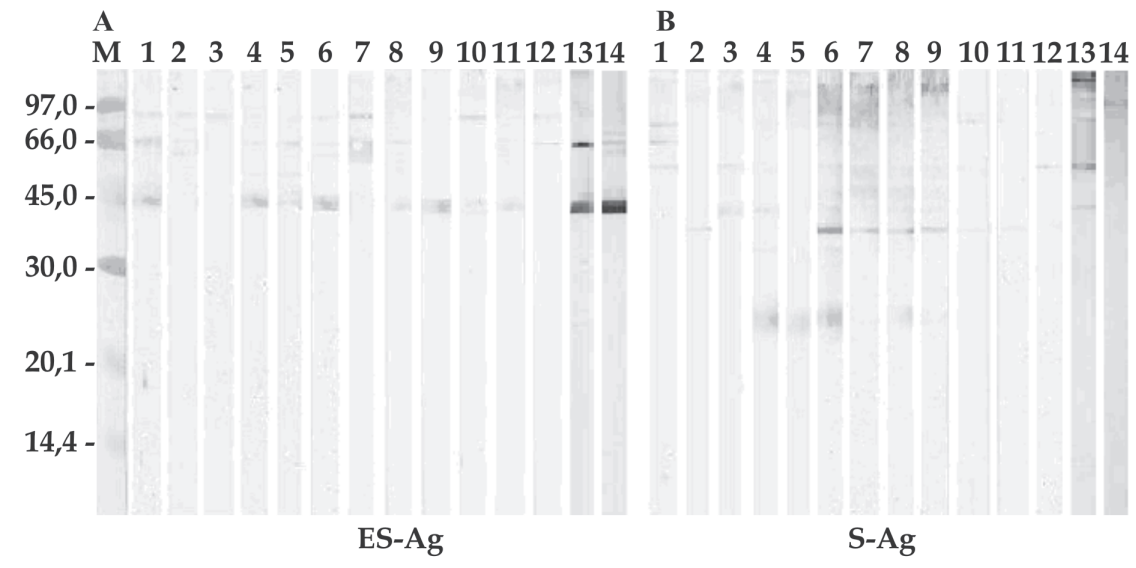

Fig. 1: immunoblotting profiles using the sera from dogs naturally infected with Echinococcus granulosus (lanes 1-12). Lane 13: serum from dog infected with Taenia hydatigena (control). Lane 14: serum from helminth-free dog (negative control). M: molecular mass marker (kDa). A: excretory-secretory antigens (ES-Ag); B: somatic antigens (S-Ag)

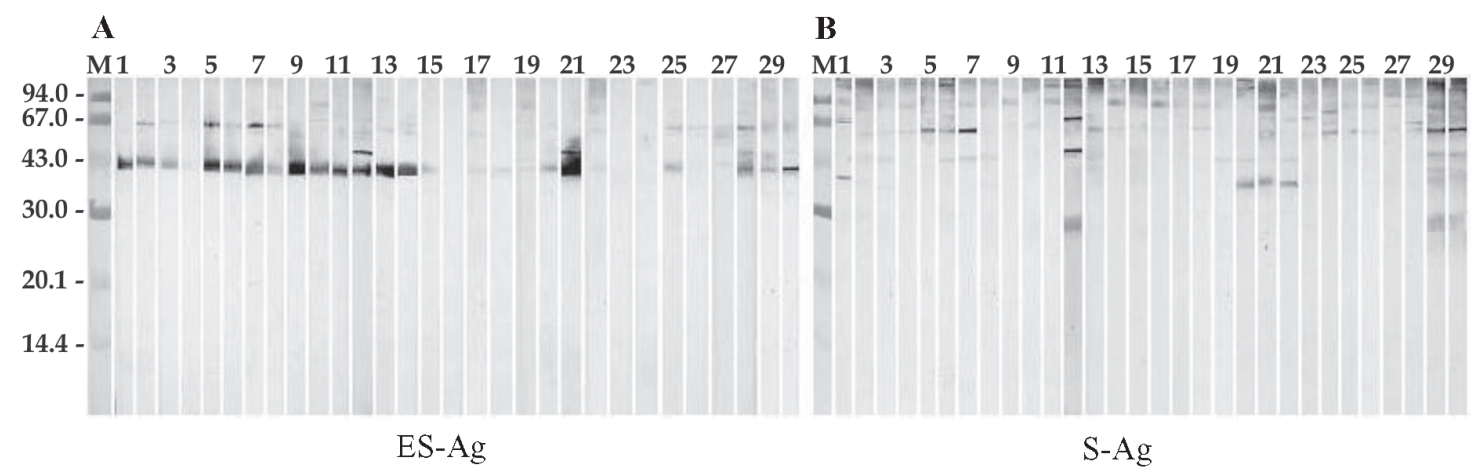

Fig. 2: immunoblotting profiles for excretory-secretory antigens (ES-Ag) and somatic antigen (S-Ag) using sera from dogs infected with helminths other than Echinococcus granulosus. Taenia spp.: lanes 1 to 8; Mesocestoides spp.: lane 9; D. caninum: lanes 10 to 14; T. canis: lanes 15 to $19 ;$ T. leonina: lanes 20 to 22; T. vulpis: lane 23; U. stenocephala: lanes 24 to 27 ; A. caninum: lanes 28 to 30 . M: molecular mass marker (kDa). A: ES-Ag; B: S-Ag

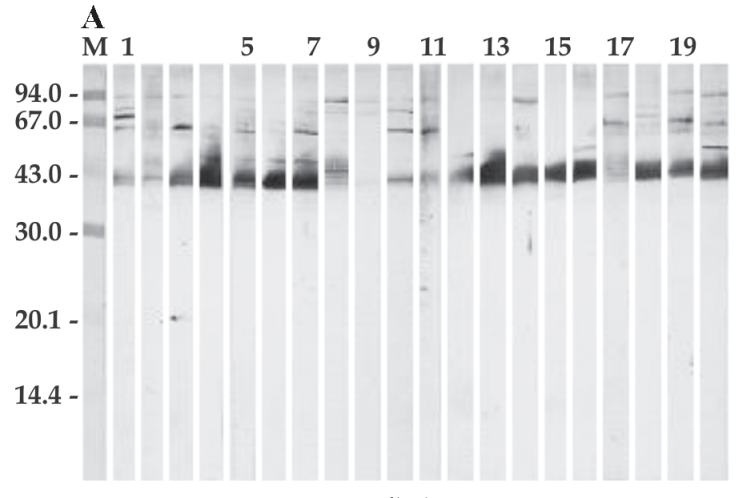

ES-Ag

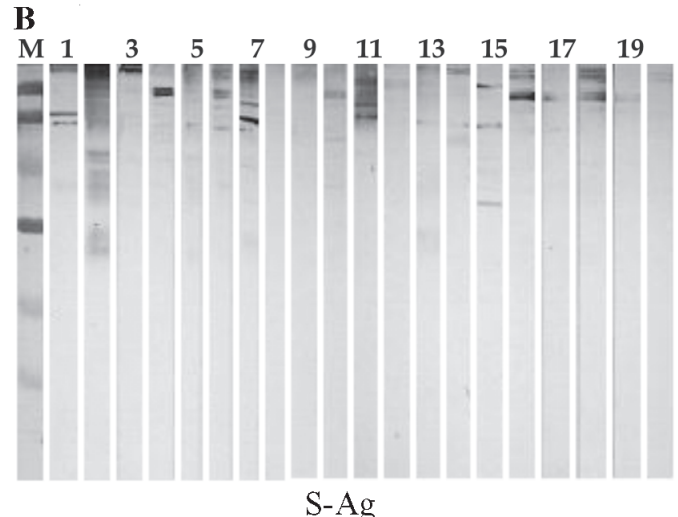

S-Ag

Fig. 3: immunoblotting profiles for excretory-secretory antigens (ES-Ag) and somatic antigens (S-Ag) using sera from helminth-free dogs. M: Molecular mass marker (kDa). A: ES-Ag; B: S-Ag 
coccosis by ELISA and/or immunoblotting (Jenkins \& Rickard 1986, Gasser et al. 1992). However, information about the characterization of ES-Ag from this parasite is very rare, which can be partially due to difficulties in obtaining enough amounts of ES-Ag. Recently, our laboratory has identified over 20 major protein components in the ES-Ag which could be distinguished by 1-dimensional SDS-PAGE and revealed apparent masses between 9 and $300 \mathrm{kDa}$ (Carmena et al. 2004). In this study, we present preliminary data about the immunochemical characterization of ES-Ag from protoscoleces of E. granulosus, which may help to identify new candidate antigens with potential for immunodiagnosis of dog echinococcosis.

Secreted products of E. granulosus adults have been characterized by immunoblotting using sera from dogs naturally infected with this cestode (Gasser et al. 1992). These authors identified three antigenic components larger than $94 \mathrm{kDa}$, two triplets of 68/94 and 39/43 kDa, and seven proteins smaller than $30 \mathrm{kDa}$. In our study, we have identified seven secreted components from E. granulosus protoscoleces ranging from 46 to $133 \mathrm{kDa}$. When $\mathrm{S}-\mathrm{Ag}$ from protoscoleces was used, Gasser et al. (1992) found antigenic proteins of $94,76,35,27$, and others smaller than $14 \mathrm{kDa}$. In our work, we have recognised 15 antigenic components ranging from 24 and $130 \mathrm{kDa}$ in the same extract. Only three of them had similar molecular masses (76, 34, and $24 \mathrm{kDa}$ ) compared to the components described by Gasser et al. (1992).

We have evaluated by immunoblotting the possible cross-reactivity of S-Ag with sera from dogs infected with

TABLE I

Immunoblotting results. Components of excretory-secretory antigens and somatic antigens recognized by different dog sera. The percentage of sera which bound to each antigenic component is expressed in brackets. Molecular masses are expressed in $\mathrm{kDa}$

\begin{tabular}{|c|c|c|c|c|c|}
\hline \multicolumn{3}{|c|}{ Excretory-secretory antigens } & \multicolumn{3}{|c|}{ Somatic antigens } \\
\hline $\begin{array}{l}\text { With } \\
\text { E. granulosus }\end{array}$ & $\begin{array}{c}\text { Other } \\
\text { parasitoses }\end{array}$ & Helminth-free & $\begin{array}{l}\text { With } \\
\text { E. granulosus }\end{array}$ & $\begin{array}{c}\text { Other } \\
\text { parasitoses }\end{array}$ & Helminth-free \\
\hline- & $\begin{array}{c}140 \\
(20 \%)\end{array}$ & - & - & $\begin{array}{c}137 \\
(27 \%)\end{array}$ & $\begin{array}{c}137 \\
(20 \%)\end{array}$ \\
\hline $\begin{array}{c}133 \\
(58 \%)\end{array}$ & - & - & $\begin{array}{c}130 \\
(33 \%)\end{array}$ & - & - \\
\hline- & - & - & $\begin{array}{c}115 / 122 \\
(\mathrm{D}, 83 \%)\end{array}$ & $\begin{array}{c}112 / 120 \\
(\mathrm{D}, 70 \%)\end{array}$ & $\begin{array}{c}113 \\
(55 \%)\end{array}$ \\
\hline- & - & - & $\begin{array}{c}103 \\
(58 \%)\end{array}$ & $\begin{array}{c}104 \\
(20 \%)\end{array}$ & - \\
\hline- & - & - & - & $\begin{array}{c}94 \\
(53 \%)\end{array}$ & $\begin{array}{c}\text { 98/104 (D) } \\
(50 \%)\end{array}$ \\
\hline $\begin{array}{c}89 \\
(92 \%)\end{array}$ & - & - & - & - & - \\
\hline- & $\begin{array}{c}85 \\
(20 \%)\end{array}$ & $\begin{array}{c}85 \\
(70 \%)\end{array}$ & $\begin{array}{c}85 \\
(42 \%)\end{array}$ & - & $\begin{array}{c}85 \\
(30 \%)\end{array}$ \\
\hline- & - & - & - & $\begin{array}{c}82 \\
(33 \%)\end{array}$ & $\begin{array}{c}81 \\
(30 \%)\end{array}$ \\
\hline- & $\begin{array}{c}76 \\
(17 \%)\end{array}$ & $\begin{array}{c}77 \\
(65 \%)\end{array}$ & $\begin{array}{c}76 \\
(42 \%)\end{array}$ & - & $\begin{array}{c}78 \\
(25 \%)\end{array}$ \\
\hline- & - & $\begin{array}{c}71 \\
(20 \%)\end{array}$ & - & $\begin{array}{c}70 \\
(30 \%)\end{array}$ & - \\
\hline- & - & $\begin{array}{c}68 \\
(60 \%)\end{array}$ & $\begin{array}{c}67 \\
(25 \%)\end{array}$ & - & - \\
\hline $\begin{array}{c}65 \\
(67 \%)\end{array}$ & $\begin{array}{c}65 \\
(10 \%)\end{array}$ & - & $\begin{array}{c}65 \\
(17 \%)\end{array}$ & $\begin{array}{c}65 \\
(17 \%)\end{array}$ & - \\
\hline $\begin{array}{c}61 \\
(25 \%)\end{array}$ & $\begin{array}{c}61 \\
(43 \%)\end{array}$ & $\begin{array}{c}61 \\
(25 \%)\end{array}$ & - & $\begin{array}{c}61 \\
(57 \%)\end{array}$ & $\begin{array}{c}60 \\
(30 \%)\end{array}$ \\
\hline $\begin{array}{c}54 \\
(17 \%)\end{array}$ & $\begin{array}{c}54 \\
(37 \%)\end{array}$ & - & $\begin{array}{c}55 \\
(67 \%)\end{array}$ & $\begin{array}{c}52 \\
(10 \%)\end{array}$ & - \\
\hline $\begin{array}{c}46 / 50(\mathrm{D}) \\
(68 \%)\end{array}$ & $\begin{array}{c}45 \\
(17 \%)\end{array}$ & $\begin{array}{c}46 \\
(40 \%)\end{array}$ & $\begin{array}{c}48 \\
(33 \%)\end{array}$ & $\begin{array}{c}46 \\
(40 \%)\end{array}$ & - \\
\hline- & $\begin{array}{l}41-43 \\
(80 \%)\end{array}$ & $\begin{array}{c}41 \\
(100 \%)\end{array}$ & $\begin{array}{c}41 / 43(\mathrm{D}) \\
(50 \%)\end{array}$ & $\begin{array}{c}41 \\
(20 \%)\end{array}$ & - \\
\hline- & - & - & $\begin{array}{c}39 \\
(67 \%)\end{array}$ & $\begin{array}{c}38 \\
(10 \%)\end{array}$ & $\begin{array}{c}39 \\
(10 \%)\end{array}$ \\
\hline- & - & - & $\begin{array}{c}34 \\
(25 \%)\end{array}$ & $\begin{array}{c}36 \\
(17 \%)\end{array}$ & - \\
\hline- & - & - & $\begin{array}{c}24 \\
(42 \%)\end{array}$ & $\begin{array}{c}26 \\
(10 \%)\end{array}$ & - \\
\hline
\end{tabular}

D: doublet; E: Echinococcus 
A

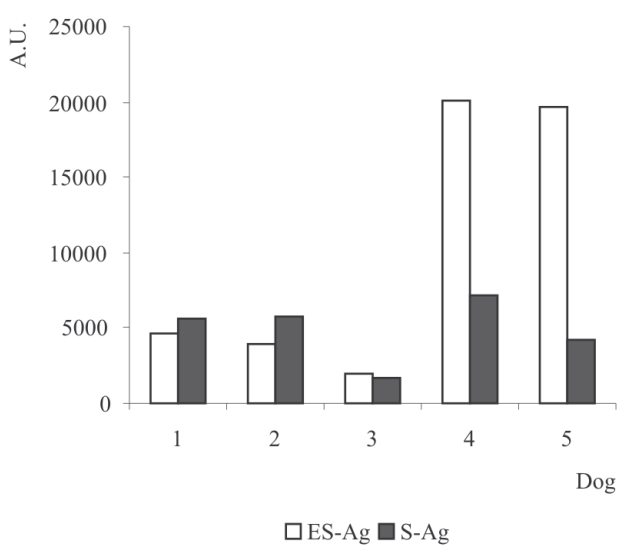

B

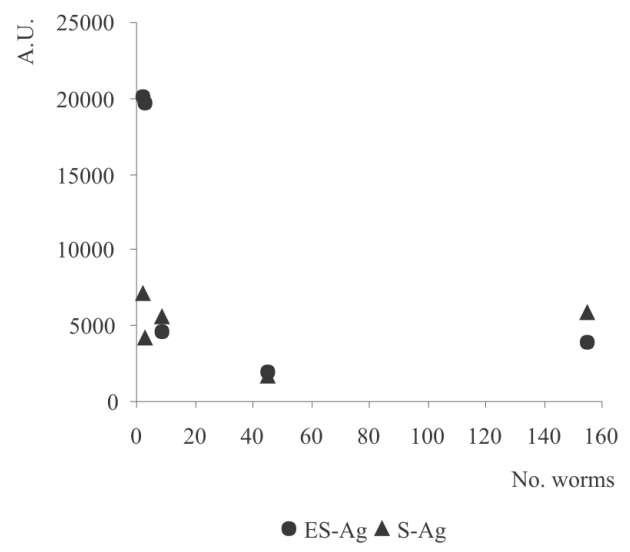

Fig. 4-A: ELISA results for different antigenic extracts using sera from dogs naturally infected with Echinococcus granulosus; B: ELISA results for different antigenic extracts considering the worm burden found at autopsy. ES-Ag: excretory-secretory antigens; S-Ag: somatic antigens; A.U.: arbitrary units
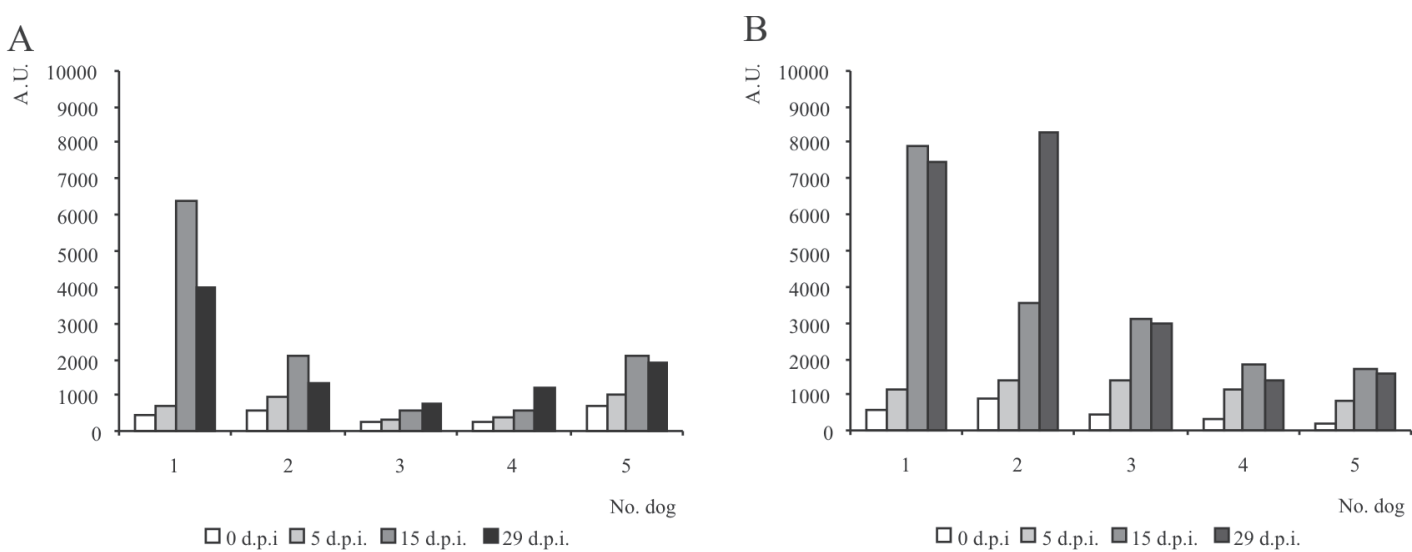

Fig. 5: ELISA results for different antigenic extracts using sera from five dogs experimentally infected with Echinococcus granulosus. Sera were obtained at different time points of infection on days $0,5,15$, and 29. A: excretory-secretory antigens (ES-Ag); B: somatic antigens (S-Ag); A.U.: arbitrary units; D.p.i.: days post-infection

helminths other than E. granulosus as well as with sera from helminth-free dogs. Using S-Ag, $40 \%$ of sera from dogs with non-echinococcal infections reacted specifically with a $46 \mathrm{kDa}$ protein, and $20 \%$ with a $41 \mathrm{kDa}$ polypeptide, which were also recognized by sera from dogs naturally infected with $E$. granulosus. Additional cross-reacting proteins of 113 , and $85 \mathrm{kDa}$ were identified by $55 \%$, and $30 \%$ of helminth-free dog sera, respectively, and to a lower degree, proteins of 78 , and $39 \mathrm{kDa}$. S-Ag with molecular masses of 130 and $67 \mathrm{kDa}$ may have diagnostic potential, since they were only identified by sera from dogs infected with E. granulosus, but not by sera from dogs with non-echinococcal infections.

On the other hand, only 4 components from ES-Ag (polypeptides of 65, 61, 54, and 45-46 kDa) showed significant cross-reactivity levels. These proteins were recognized by $10-43 \%$ of sera from dogs infected with helminths other than E. granulosus or by sera from helminthfree dogs. In this antigenic extract, 2 proteins of 89 and 50 $\mathrm{kDa}$, respectively, were recognized by sera from dogs in- fected with E. granulosus only. Interestingly, the component of $89 \mathrm{kDa}$ was identified by $92 \%$ of sera that were tested. This fact suggests that this protein might be a promising diagnostic antigen that could be used in immunological tests for the detection of E. granulosus in dogs. These data demonstrate that, although S-Ag showed the highest specific antibody levels in ELISA, ES-Ag is more specific than S-Ag for immunodiagnosis of dog echinococcosis.

It was difficult to highlight specific recognition patterns attributable to individual infections, except in the case of the sera from dogs infected with Toxascaris leonina. All of them showed a specific protein of $36 \mathrm{kDa}$ when using S-Ag (Fig. 2B, lanes 20 to 22).

The lack of specificity of the 41-43 kDa component from the excreted products of E. granulosus adults has been previously described by Gasser et al. (1992). In our work, we have corroborated this result, identifying this antigenic protein both in ES-Ag and S-Ag. Recently, we have also found the 41-43 kDa component in the ES-Ag 
by immunoblotting with non-hydatidic human sera, including sera from individuals with other parasitoses, from individuals with non-parasitological pathologies and from healthy donors (Carmena et al. 2004).

ELISA results for sera from dogs infected with $E$. granulosus showed that highest worm burdens are not always corresponding with highest specific antibody levels, especially when ES-Ag is used (Gasser et al. 1992, 1993). This finding seems to demonstrate that there is no relationship between the number of worms in the intestine and the circulating antibody level, confirming previous results of Jenkins and Rickard (1985), Gasser et al. $(1988,1992,1994)$ and Jenkins et al. $(1990,1991)$. This fact may either be due to the sequestration of antibodies and the formation of circulating immunocomplexes (Gasser et al. 1988, 1993, Spinelli et al. 1996), or to immune evasion mechanisms of the parasite (Gasser et al. 1992, 1994), or to a low immune response of the host (Gasser et al. 1988, 1993, 1994). Host nutritional status may also have an impact on the antibody levels (Jenkins et al. 1991, Gasser et al. 1992). On the other hand, the broad differences of antibody levels found among the studied dog sera also may reflect the influence by physiological and environmental factors, like re-infection or co-infection with other parasite species.

In ELISA, sera from dogs experimentally infected with E. granulosus showed less variability regarding the levels of specific antibodies than sera from dogs with natural infections (Figs 4 and 5). This may be due to the standardized environmental conditions under which these animals were maintained. The highest specific antibody levels were reached using S-Ag, especially when sera from dogs experimentally infected were assayed. These results are in agreement with those obtained by Benito et al. (2001), who found higher discrimination levels between positive and negative controls using S-Ag than with ESAg or hydatid cyst fluid as antigenic extracts.

We conclude that ES-Ag from protoscoleces of $E$. granulosus contain potential diagnostic antigens to be used in the immunodiagnosis of canine echinococcosis. In particular, the protein of $89 \mathrm{kDa}$ has evidenced the most promising features. However, a more comprehensive analysis will be necessary to determine more accurately the significance of these observations, since only a comparatively low number of sera was available for the present study. Further studies to clone and express individual protein components from secreted products of protoscoleces which display both high immunoreactivity and specificity: may be of great interest for the diagnosis of dog echinococcosis.

\section{ACKNOWLEDGEMENTS}

To Prof. Murray E Selkirk and Dr Sonja Kock (Department of Biological Sciences, Imperial College London, UK) for their critical revision of this manuscript.

\section{REFERENCES}

Allan JC, Craig PS, García Noval J, Mencos F, Liu D, Wang Y, Wen H, Zhou P, Stringer R, Rogan M, Zeyhle E 1992. Coproantigen detection for immunodiagnosis of echinococcosis and taeniasis in dogs and humans. Parasitology 104: 347-355.
Benito A, Carmena D, Spinelli P, Postigo I, Martínez J, Estíbalez JJ, Martín de la Cuesta F, Guisantes JA 2001. The serological diagnosis of canine echinococcosis by an enzyme immunoassay useful for epidemiological surveys. Res Rev Parasitol 61: 17-23.

Carmena D, Benito A, Postigo I, Arteaga J, Martínez J, Guisantes JA 2002. Short term culture of protoscoleces to obtain excretory-secretory proteins of Echinococcus granulosus. Res Rev Parasitol 62: 84-88.

Carmena D, Martínez J, Benito A, Guisantes JA 2004. Characterization of excretory-secretory products from protoscoleces of Echinococcus granulosus and evaluation of their potential for immunodiagnosis of human cystic echinococcosis. Parasitology 129: 371-378.

Deplazes P, Gottstein B, Eckert J, Jenkins DJ, Ewald D, Jiménez-Palacios S 1992. Detection of Echinococcus coproantigens by enzyme-linked immunosorbent assay in dogs, dingoes and foxes. Parasitol Res 78: 303-308.

Fraser A, Craig PS 1997. Detection of gastrointestinal helminth infections using coproantigen and molecular diagnostic approaches. J Helminthol 71: 103-107.

Gasser RB, Jenkins DJ, Heath DD, Lawrence SB 1992. Use of Echinococcus granulosus worm antigens for immunodiagnosis of Echinococcus granulosus infection in dogs. Vet Parasitol 45: 89-100.

Gasser RB, Jenkins DJ, Paolillo E, Parada L, Cabrera P, Craig PS 1993. Serum antibodies in canine echinococcosis. Int $J$ Parasitol 23: 579-586.

Gasser RB, Lightowlers MW, Obendorf DL, Jenkins DJ, Rickard MD 1988. Evaluation of a serological test system for the diagnosis of natural Echinococcus granulosus infection in dogs using E. granulosus protoscolex and oncosphere antigens. Australian Vet J 65: 369-373.

Gasser RB, Lightowlers MW, Rickard MD 1989. Identification of protein components of Echinococcus granulosus protoscolex antigens for specific serodiagnosis of Echinococcus granulosus in dogs. Parasite Immunol 11: 279-291.

Gasser RB, Lightowlers MW, Rickard MD 1991. Echinococcus granulosus: antigenic proteins in oncospheres and on the surface of protoscoleces identified by serum antibodies from infected dogs. Res Vet Sci 50: 340-345.

Gasser RB, Parada L, Acuna A, Burges C, Laurenson MK, Gulland FMD, Reichel MP, Paolillo E 1994. Immunological assesment of exposure to Echinococcus granulosus in a rural dog population in Uruguay. Acta Trop 58: 179-185.

Howell MJ 1986. Cultivation of Echinococcus species in vitro. In RCA Thompson, The Biology of Echinococcus and Hydatid Disease, George Allen \& Unwin, London, p. 143-163.

Jenkins DJ, Rickard MD 1985. Specific antibody responses to Taenia hydatigena, Taenia pisiformis and Echinococcus granulosus infection in dogs. Australian Vet J 62: 72-78.

Jenkins DJ, Rickard MD 1986. Specific antibodies responses in dogs experimentally infected with Echinococcus granulosus. Am J Trop Med Hyg 35: 345-349.

Jenkins DJ, Fraser A, Bradshaw H, Craig PS 2000. Detection of Echinococcus granulosus coproantigens in Australian canids with natural or experimental infection. J Parasitol 86: 140145 . 
Jenkins DJ, Gasser RB, Romig T, Zeyhle E 1991. Antibody responses against natural Taenia hydatigena infection in dogs in Kenya. Int J Parasitol 21: 251-253.

Jenkins DJ, Gasser RB, Zeyhle E, Romig T, Macpherson CNL 1990. Assessment of a serological test for the detection of Echinococcus granulosus infection in dogs in Kenya. Acta Trop 47: 245-248.

Laemmli UK 1970. Cleavage of structural proteins during the assembly of the head of bacteriophage T4. Nature 227: 680-685.

Rafiei A, Craig PS 2002. The immunodiagnostic potential of protoscolex antigens in human cystic echinococcosis and the possible influence of parasite strain. Ann Trop Med Parasitol 96: 383-389.

Smyth JD, Davies Z 1974. In vitro culture of the strobilar stage of Echinococcus granulosus (sheep strain): a review of basic problems and results. Int J Parasitol 4: 631-644.
Spinelli P, Carol H, Nieto A 1996. Niveles de anticuerpos y antígenos circulantes en perros con infección natural y experimental por Echinococcus granulosus. Inmunología 15: 21-29.

Towbin H, Staehelin T, Gordon J 1979. Electrophoretic transfer of proteins from polyacrylamide gels to nitrocellulose sheets: procedure and some applications. Proc Nat Acad Sci USA 76: 4350-4354.

Wachira T, McPherson CNL, Gathuma JM 1990. Hydatid disease in the Turkana District of Kenya VII. Analysis of the infection pressure on definitive and intermediate hosts of E. granulosus. Ann Trop Med Parasitol 84: 361-368.

WHO 2001. WHO/OIE Manual on Echinococcosis in Humans and Animals: a Public Health Problem of Global Concern (eds. J Eckert, MA Gemmell, F-X Meslin, ZS Pawlowski), WHO/OIE, Paris. 
